\title{
Boston type I keratoprosthesis from patient selection through postoperative management: a review for the keratoprosthetic surgeon
}

This article was published in the following Dove Press journal:

Clinical Ophthalmology

14 March 2016

Number of times this article has been viewed

\author{
Samantha L Williamson' \\ M Soledad Cortina ${ }^{2}$ \\ 'Department of Ophthalmology, \\ Kaiser Permanente Mid-Atlantic \\ Medical Group, Baltimore, MD, USA; \\ ${ }^{2}$ Department of Ophthalmology and \\ Visual Sciences, University of Illinois \\ Eye and Ear Infirmary, Chicago, \\ IL, USA
}

\begin{abstract}
For the anterior segment surgeon, the implantation of Boston type 1 keratoprosthesis is a multistep process that begins with careful patient selection. Success depends on thorough preoperative evaluation, detailed surgical planning, and frequent postoperative follow-up. New practice patterns have emerged for each of these phases as the international experience with keratoprosthesis grows. This review details special considerations that can improve outcomes and also allow surgeons to consider its use in challenging patient populations at each step.
\end{abstract}

Keywords: Keratoprosthesis, aniridia, ocular cicatricial pemphigoid, Stevens-Johnson syndrome

\section{Introduction}

The Boston type 1 keratoprosthesis (Kpro) has undergone significant advances in prosthetic design and surgical technique in the last decade. These changes have been accompanied by rising numbers of Kpro implantation for expanding etiologies, and even the adoption of the Kpro as a primary procedure for selected indications. Internationally, single and multicenter groups have published short- and intermediate-term Kpro outcomes with attention to specific conditions. These results underscore the critical importance of careful patient selection and perioperative planning. We will review special considerations regarding patient selection, preoperative evaluation, surgical planning, and postoperative follow-up for Boston type 1 Kpro.

\section{Patient selection}

The success of the device begins with appropriate patient selection for Kpro implantation. For a potential candidate, the surgeon should consider the etiology of vision loss, visual acuity of both the operative and fellow eye, lid position and ocular surface status, and concomitant ocular and systemic diseases. Patient reliability is an important factor, as compliance with medications and follow-up is critical for device retention. Similarly, patient expectations must be assessed at the outset.

Outcomes of the Boston type 1 Kpro have been associated with the preoperative diagnosis (Table 1). Studies suggest patients with Stevens-Johnson syndrome and ocular cicatricial pemphigoid fare worse than those with non-cicatrizing etiologies, such as repeated graft failure for infections or dystrophies, with chemical burns and aniridia falling somewhere in the middle of the spectrum. ${ }^{1,2}$ The Boston type 1 keratoprosthesis Study Group identified three risk factors for Kpro device loss, including autoimmune etiology (eg, ocular cicatricial pemphigoid, Stevens-Johnson syndrome), ocular surface exposure
Correspondence: M Soledad Cortina Department of Ophthalmology and Visual Sciences, University of Illinois Eye \& Ear Infirmary, 1855 W Taylor Street, Suite 1059, Chicago, IL 606I2, USA

$\mathrm{Tel}+\mathrm{I} 3129968937$

Fax + I 3123555254

Email mcortina@uic.edu (c) (1) (-) 2016 Williamson and Cortina. This work is published and licensed by Dove Medical Press Limited. The full terms of this license are available at https://www.dovepress.com/terms.php (c) hereby accept the Terms. Non-commercial uses of the work are permitted without any further permission from Dove Medical Press Limited, provided the work is properly attributed. For permission for commercial use of this work, please see paragraphs 4.2 and 5 of our Terms (https://www.dovepress.com/terms.php). 
Table I Table summarizing published Kpro outcomes based on the preoperative diagnosis

\begin{tabular}{|c|c|c|c|}
\hline Publication & $\begin{array}{l}\text { Autoimmune disease } \\
\text { (SJS/TEN, OCP, RA) }\end{array}$ & $\begin{array}{l}\text { Chemical injuries } \\
\text { and aniridia }\end{array}$ & Non-cicatrizing indications \\
\hline Khan et al' & $\begin{array}{l}\text { Device retention at } 2 \text { years: } \\
33 \% \text { SJS, } 72 \% \text { OCP } \\
\text { At } 5 \text { years: } 0 \% \text { SJS, } 43 \% \text { OCP }\end{array}$ & $\begin{array}{l}\text { Device retention at } 2 \text { years: } \\
64 \% \text { chemical burns } \\
\text { At } 5 \text { years: } 25 \%\end{array}$ & $\begin{array}{l}\text { Device retention at } 2 \text { years: } 83 \% \\
\text { At } 5 \text { years: } 68 \%\end{array}$ \\
\hline Greiner et $\mathrm{al}^{2}$ & $\begin{array}{l}\text { Eyes achieving } V A \geq 20 / 200: 50 \% \\
\text { Device retention: } 67 \%\end{array}$ & $\begin{array}{l}\text { Eyes achieving } V A \geq 20 / 200 \text { : } \\
90 \% \text { chemical burns, } 80 \% \text { aniridia } \\
\text { Device retention: } 100 \% \text { chemical } \\
\text { burns, } 80 \% \text { aniridia }\end{array}$ & $\begin{array}{l}\text { Eyes achieving } V A \geq 20 / 200: 84 \% \\
\text { Device retention: } 84 \%\end{array}$ \\
\hline Ciolino et $\mathrm{al}^{3}$ & Kpro failure rate: $29 \%$ & $\begin{array}{l}\text { Kpro failure rate: } 3.2 \% \text { chemical } \\
\text { injury, } 14.3 \% \text { anirida }\end{array}$ & Kpro failure rate: $0 \%$ \\
\hline Nouri et $\mathrm{al}^{5}$ & $\begin{array}{l}\text { Endophthalmitis rate: } 39 \% \text { SJS, } \\
\text { I9\% OCP }\end{array}$ & $\begin{array}{l}\text { Endophthalmitis rate: } \\
7 \% \text { chemical burns }\end{array}$ & Endophthalmitis rate: $0.025 \%$ \\
\hline
\end{tabular}

Abbreviations: SJS, Stevens-Johnson syndrome; TEN, toxic epidermal necrolysis; OCP, ocular cicatrical pemphigoid; RA, rheumatoid arthritis; Kpro, keratoprosthesis; $\mathrm{VA}$, visual acuity.

requiring tarsorrhaphy, and increased number of prior failed penetrating keratoplasties. ${ }^{3}$ Given the poor prognosis of a traditional penetrating keratoplasty in some conditions, such as those with limbal stem cell deficiency, Kpro as a primary procedure may be considered in certain patients. ${ }^{4}$

Device survival is shortened in patients with poor ocular surface stability, whether from cicatrizing disease or limbal stem cell dysfunction (LSCD), with increased rates of complications. Preoperative ocular surface disease, particularly in Stevens-Johnson syndrome and ocular cicatricial pemphigoid, is an identified risk factor for endophthalmitis following Kpro placement. ${ }^{5}$ Similarly, increased rates of sterile keratolysis are reported in patients with underlying autoimmune disease and retroprosthetic membranes (RPMs). ${ }^{6} \mathrm{RPM}$ development, in turn, is associated with aniridia and infectious keratitis as the indication for Kpro placement. ${ }^{?}$

Although autoimmune diseases were initially considered a relative contraindication due to the heightened risk of complications, recent improvements in postoperative management have allowed increased confidence in the placement of Kpro in very select patients with reasonable tear production and controlled ocular surface inflammation. ${ }^{8,9}$ However, the surgeon should proceed with caution, armed with a tailored management plan, after discussing the associated risks with the patient. ${ }^{8,9}$

Regardless of the specific indication, a detailed discussion of the procedure should be carried out with all patients prior to surgery, including the risks of device extrusion, endophthalmitis, and glaucoma progression, as well as realistic expectations of visual rehabilitation. Of particular importance is that the patient understands the commitment to frequent postoperative visits, as well as the necessity for indefinite postoperative prophylactic topical medications.

\section{Preoperative evaluation}

A thorough office examination is a key step in successful Kpro placement, including an assessment of visual potential. The World Health Organization criteria stipulates that a patient be monocular or functionally blind in both eyes to be considered eligible for a Boston Kpro; however, many surgeons now offer Kpro surgery despite relatively good vision in the contralateral eye. This evolution in practice pattern is largely due to improving rates of postoperative visual function, restoration of binocularity, and enhanced cosmesis. ${ }^{10,11}$ A recent study evaluated patient responses to the National Eye Institute Visual Function Questionnaire 25 (NEI VFQ-25) following Kpro implantation, and found a significant improvement in quality-of-life measures even in those patients with vision better than 20/200 in their nonsurgical eye. ${ }^{12}$ To optimize outcomes, patients should possess certain essential characteristics, including adequate lid anatomy, good blink function, controlled ocular surface inflammation, and a sufficiently moist ocular surface.

Fornices should be evaluated and able to accommodate a large bandage contact lens after surgery. Long-term use of a bandage lens postoperatively can prevent drying of the ocular surface, dellen formation, and corneal melts, and absence of a lens is an independent risk factor for postoperative complications of infections and corneal melts. ${ }^{13}$ Thus, some patients may benefit from fornix reconstruction as a first stage procedure in preparation for implantation of the Boston Kpro (Figure 1). Oculoplastic consultation may also be indicated in patients with poor lid closure or lagophthalmos to minimize exposure.

A careful corneal and anterior segment examination must be performed. As discussed previously, ocular surface 

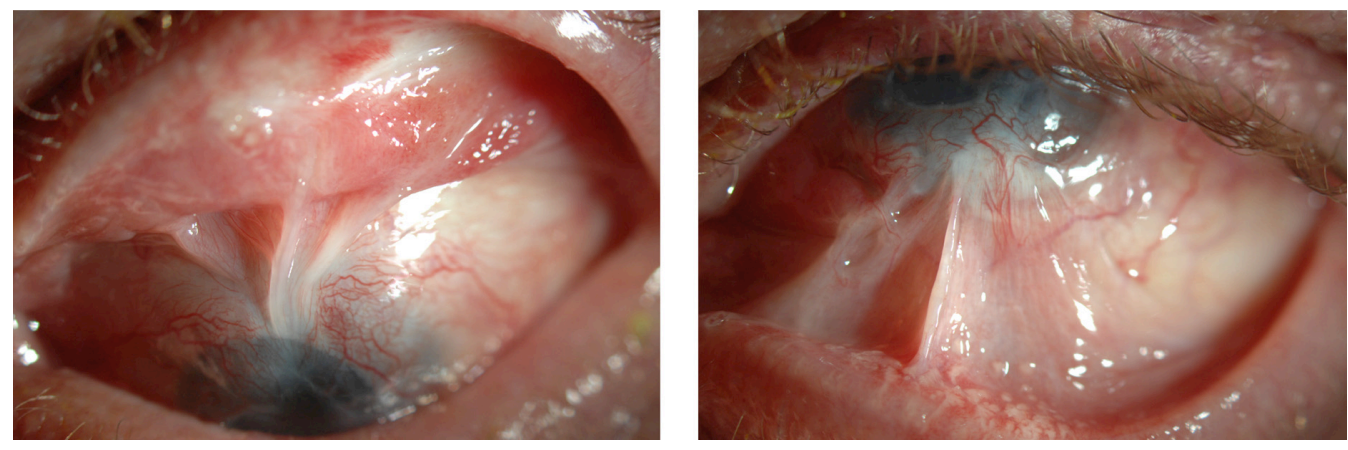

Figure I Forniceal scarring documented in a patient during a preoperative evaluation for keratoprosthesis. Note: These patients should undergo fornix reconstruction to allow bandage contact lens placement.

stability is integral to device survival. ${ }^{5}$ Tear production can be measured with Schirmer testing, and goblet cell and meibomian gland function evaluated to assess all three layers of the tear film. Limbal stem cell function is also critical, and often compromised in patients with Stevens-Johnson syndrome, aniridia, chemical burns, and ocular cicatricial pemphigoid. Clinical findings of LSCD include peripheral corneal vascularization, advancement of conjunctival epithelium onto the cornea, and the presence of goblet cells on the corneal surface. ${ }^{14}$ If LSCD is suspected, strategies for epithelial healing must be part of the surgical plan. Conjunctival scarring should be noted, as it may affect contact lens fit or placement of a planned tube shunt.

A thorough history can help the surgeon determine the possibility of significant optic nerve dysfunction, retinal pathology, or dense amblyopia. B-scan ultrasonography should be performed to evaluate retinal anatomy if the posterior segment cannot be visualized. It is critical to assess the adequacy of intraocular pressure (IOP) control preoperatively to determine the need for additional glaucoma procedures. A more complete picture can be established by collecting multiple IOP measurements, the number and duration of topical antihypertensives, and history of any prior filtering procedures or glaucoma lasers. Physicians may attempt to quantify preexisting optic nerve damage, but optic nerve head optical coherence tomography (OCT) and automated visual field testing are often precluded by poor preoperative vision and a limited view to the posterior segment. Significant optic nerve cupping can sometimes be seen on B-scan ultrasound. A confrontation visual field should be done to ensure a patient has light perception with projection. Peripheral anterior synechiae and angle anatomy can be evaluated by anterior segment OCT (AS-OCT), if available.

Lens' status must be determined to order the Boston type 1 Kpro with the appropriate refractive power. The Boston Kpro is available in either an aphakic or pseudophakic version, and surgeons should consider preoperatively which of these will be implanted. If a patient is phakic, a lensectomy must be performed, and an aphakic Kpro is implanted or an intraocular lens with a pseudophakic model according to the surgeon's preference. As in standard cataract surgery, the goal should be total preservation of the posterior capsule. If the patient is pseudophakic, implant stability and chamber depth should be assessed and can be evaluated with AS-OCT or ultrasound biomicroscopy. Stable posterior chamber lenses may be left in place; however, anterior chamber or unstable lenses should be explanted. If an aphakic Kpro is planned, the axial length of the eye should be measured by a scan. The Boston type 1 Kpro is available in $0.5 \mathrm{~mm}$ increments of axial length (Figure 2). ${ }^{15}$

\section{Surgical planning}

The Kpro surgeon and patient benefit from access to a multispecialist team familiar with Kpro implantation and follow-up, as these patients commonly need care for glaucoma, oculoplastic, and retinal issues. Often, several procedures can be combined to allow the best chance for visual recovery, device retention, and IOP control.

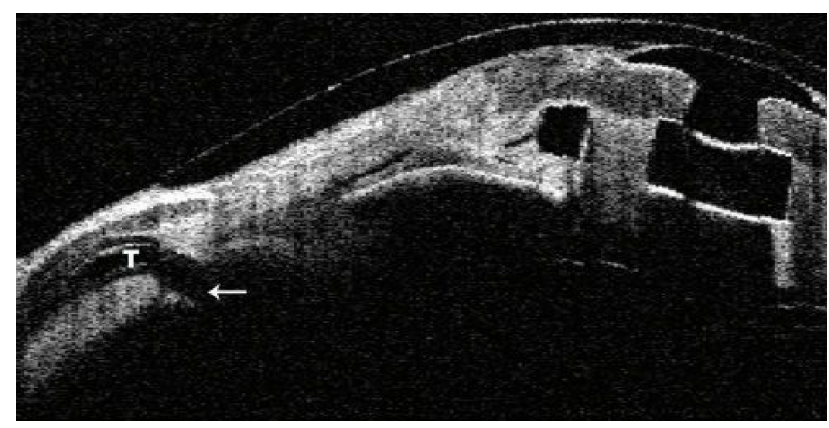

Figure 2 Anterior segment OCT demonstrating placement of a glaucoma drainage implant (arrow) in the pars plana.

Abbreviations: OCT, optical coherence tomography; T, trabecular meshwork. 
Adnexal and lid anomalies noted during the preoperative evaluation may prompt an oculoplastic referral. Procedures can be carried out during or prior to Kpro implantation, in efforts to minimize postoperative inflammation. Several strategies are available to promote epithelial healing in patients with LSCD or a dry, inflamed ocular surface. Persistent epithelial defects, a frequent complication in LSCD patients, must be taken seriously as they are associated with sterile keratolysis and device extrusion. ${ }^{16}$ Temporary or permanent partial tarsorrhaphies may be considered at the time of Kpro implantation. Ocular surface toxicity from the postoperative drop regimen can be minimized by using preservative-free formulations and limiting the number of topical medications. Punctal plugs or cautery may improve ocular surface moisture. An adequate contact lens fit is necessary, and a contact lens specialist familiar with keratoprostheses is invaluable, as often multiple fittings or a custom lens may be required. ${ }^{17}$ Scleral or hybrid lenses may be useful in challenging patients in whom other measures fail.

Uncontrolled IOP or the use of maximum medical antihypertensive therapy preoperatively should alert the clinician to consider a simultaneous glaucoma procedure, such as a tube shunt, at the time of Kpro implantation. In addition, glaucoma drainage device implantation can be also considered for aniridic patients without a history of glaucoma given that their high risk of glaucoma development is further increased by Kpro implantation. Tubes may be implanted either in the anterior chamber or ciliary sulcus without vitrectomy, or as a pars plana tube with vitrectomy (Figure 3). ${ }^{18,19}$ Conjunctival scarring, crowded anterior chambers with iridocorneal adhesions, and the need for a good bandage contact lens fit postoperatively are considerations in deciding the position of tube placement. Reported outcomes from these combined procedures

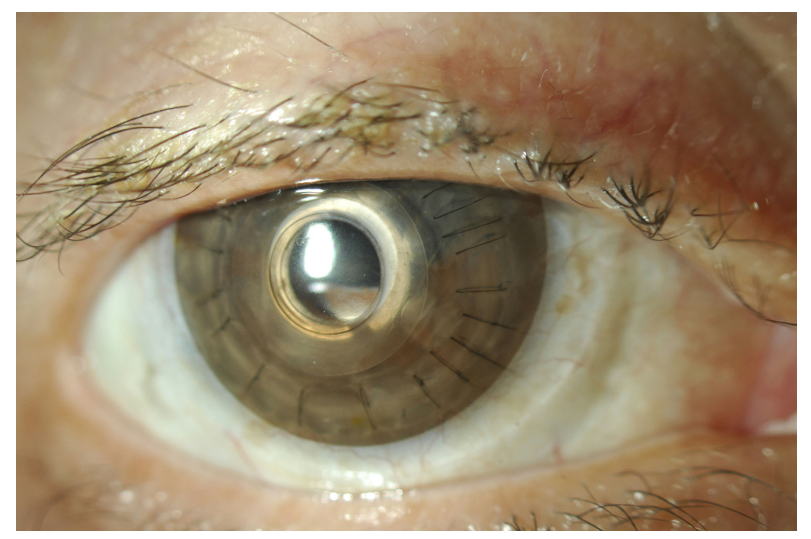

Figure 3 Bandage contact lens tinted to match the fellow iris and improve cosmesis. have been successful in controlling IOP with low risk of complications. ${ }^{20}$ Similarly, patients who have significant retinal history or an unclear retinal status given poor view to the posterior segment preoperatively may benefit from concurrent vitrectomy. ${ }^{21}$

The back plate is available in either Polymethyl methacrylate (PMMA) or titanium in the snap-on version. Originally the back plate was made of PMMA, but titanium, a newer option, can be machined to be thinner than its PMMA counterparts, potentially reducing the risk of RPM formation and anterior chamber congestion. ${ }^{22}$ Titanium is nonferromagnetic and compatible with magnetic resonance imaging, and studies demonstrate that the back plate can be colored to achieve better cosmesis via electrochemical anodization. ${ }^{23}$ Potential disadvantages of titanium are the metallic artifact created on AS-OCT that makes visualization of the angle anatomy more difficult, unlike PMMA, and a worse cosmetic appearance.

Two size options exist for the diameter of the back plate: 7 or $8.5 \mathrm{~mm}$. In patients with small corneas, short axial lengths or a crowded anterior chamber, the surgeon may request the $7 \mathrm{~mm}$ back plate for better sizing. The newer click-on Boston type $1 \mathrm{Kpro}$ is only available with an $8.5 \mathrm{~mm}$ titanium back plate, and does not require a separate locking ring.

\section{Postoperative management}

Implantation is only one aspect of Kpro management, and close, lifetime follow-up is critical for device survival. Patients must understand preoperatively that a commitment to frequent monitoring and drop maintenance is linked to implant success. More than a decade of international experience with postoperative complications offers insight into their prevention and management. In addition, improved imaging techniques provide a better understanding of the interactions between the device and host anatomy.

Behlau et al demonstrated that daily, topical antibacterial prophylaxis in KPro patients significantly reduces the risk of endophthalmitis. In the USA, the rate declined by $75 \%$ following the widespread adoption of long-term daily antibiotic use..$^{24}$ Regimens differ among Kpro surgeons, but agents should cover for Gram-positive organisms, the most common culprit, and Gram-negative microbes. Massachusetts Eye and Ear Infirmary (MEEI) has recommended daily dosing of compounded vancomycin (concentration of $14 \mathrm{mg} / \mathrm{mL}$ ) plus a fourth-generation fluoroquinolone, to be increased to twice daily in patients with autoimmune disease. The fluoroquinolone may be substituted for another antibiotic, such as trimethoprim/polymyxin $\mathrm{B}$, and long-term vancomycin use 
may be limited to cases with autoimmune disease, chemical burns, and only eyes. ${ }^{25}$ Cost, frequency of dosing, and patient compliance may influence drop selection. ${ }^{24,26}$ Fungal keratitis and endophthalmitis remain rare, and no consensus exists regarding routine fungal prophylaxis. In climates in which fungal keratitis is endemic, MEEI recommends short cycles of an antifungal agent. Natamycin $5 \%$ or compounded amphotericin $0.15 \%$ may be given twice daily for 1 week every 2-3 months. ${ }^{27}$ An additional option to augment antimicrobial preventive care is to instill one drop of $5 \%$ povidone iodine at each visit. ${ }^{28}$

The value of a long-term bandage contact lens in Kpro patients is manifold. As discussed earlier, a contact lens protects the corneal surface surrounding the anterior implant from desiccation, epithelial breakdown, and melt. ${ }^{29}$ These complications, in turn, place the patient at risk of infectious keratitis, sterile keratolysis with implant extrusion, and endophthalmitis. In addition, a lens often improves patient comfort, cosmesis, and glare, as well as addresses any refractive errors. Tinted contact lenses may be effectively used to reduce light scatter and glare (Figure 4). ${ }^{30}$ Bandage lenses, however, are not without complications. Protein deposits and inflammatory biofilms may develop, and lenses must be routinely changed. No consensus exists as to the ideal wear schedule of bandage contact lenses in Kpro. Typically, contact lenses are exchanged every 3-4 months, but may

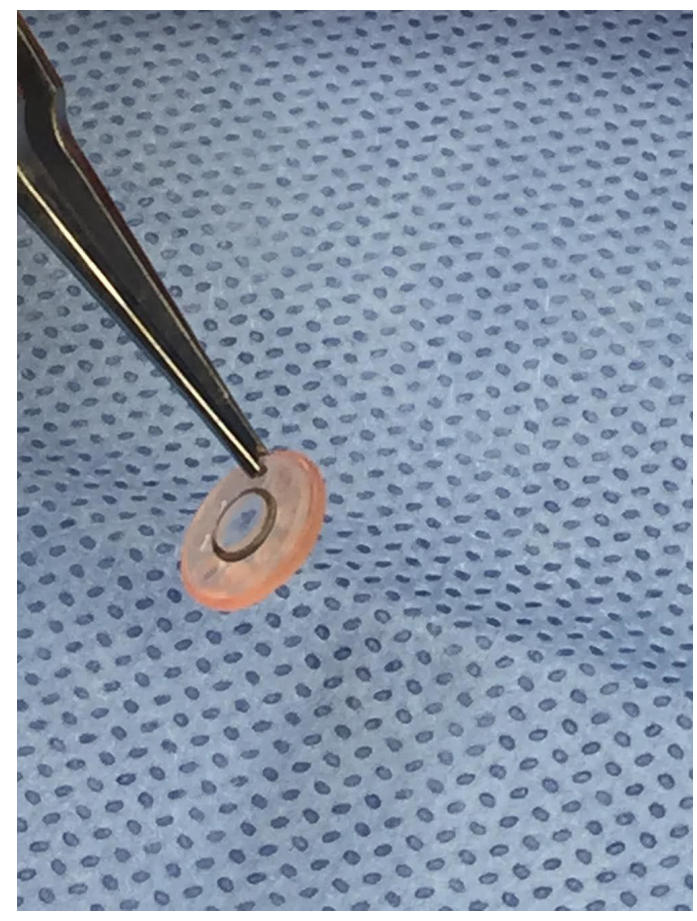

Figure 4 Intraoperative photo of assembled keratoprosthesis prior to implantation, including optic, trephinated corneal graft, and back plate. be discarded at different intervals depending on individual patient characteristics. ${ }^{28}$

Advances in the imaging techniques of AS-OCT and ultrasound biomicroscopy allow in vivo imaging of the Boston type $1 \mathrm{Kpro}$. Spectral domain, high-resolution AS-OCT can demonstrate the extent and thickness of RPMs, epithelium over the anterior Kpro plate, periprosthetic gaps, thinning in the corneal graft, angle closure, peripheral anterior synechiae, and associated anterior chamber shallowing..$^{31,32}$ Often, these entities may not be easily appreciated on clinical exam. An imaging protocol consisting of cross-sectional scans of the device and anterior chamber over $360^{\circ}$ allows serial comparison over time. ${ }^{33}$ In patients with persistent epithelial defects, AS-OCT can assess for corneal graft thinning and imminent back plate exposure. In some patients, pooling of fluorescein may be seen beneath the anterior optic, suggestive of a gap between the corneal carrier and posterior surface of the device front plate. ${ }^{34} \mathrm{AS}-\mathrm{OCT}$ may be helpful to distinguish corneal thinning as the cause versus asymmetrical seating of the device.

Development or progression of glaucoma is one of the leading causes of vision loss following Kpro implantation, and its detection may be difficult. ${ }^{35}$ Progressive closing of the angle on AS-OCT has been demonstrated in the majority of Kpro patients in several studies (Figure 5). ${ }^{33,36}$ The correlation between angle closure and increased IOP is still unclear and the subject of further study, but it may represent one mechanism of progression in these patients. Serial optic nerve OCT and optic disc photos as well as functional testing with visual fields are recommended at intervals shorter than those utilized for the follow-up of other forms of glaucoma. Posterior segment OCT can monitor for cystoid macular edema, an often under-recognized but treatable complication in this group of patients. As the AS-OCT cannot visualize posterior to the pigmented iris tissue, ultrasound biomicroscopy may be used to image glaucoma tube shunts, posterior chamber intraocular lens implants, and other structures behind the iris plane. ${ }^{37}$

\section{Conclusion}

In conclusion, careful preoperative evaluation, surgical planning, and postoperative management improve outcomes of the Boston type 1 Kpro implantation. Treatment plans should be tailored for each patient based on their presenting diagnosis and clinical features. Multidisciplinary care, involving glaucoma, retinal, oculoplastic, and contact lens specialists, is often required. Finally, the patient is a key member of the team, and must be committed to long-term care of their prosthetic. 

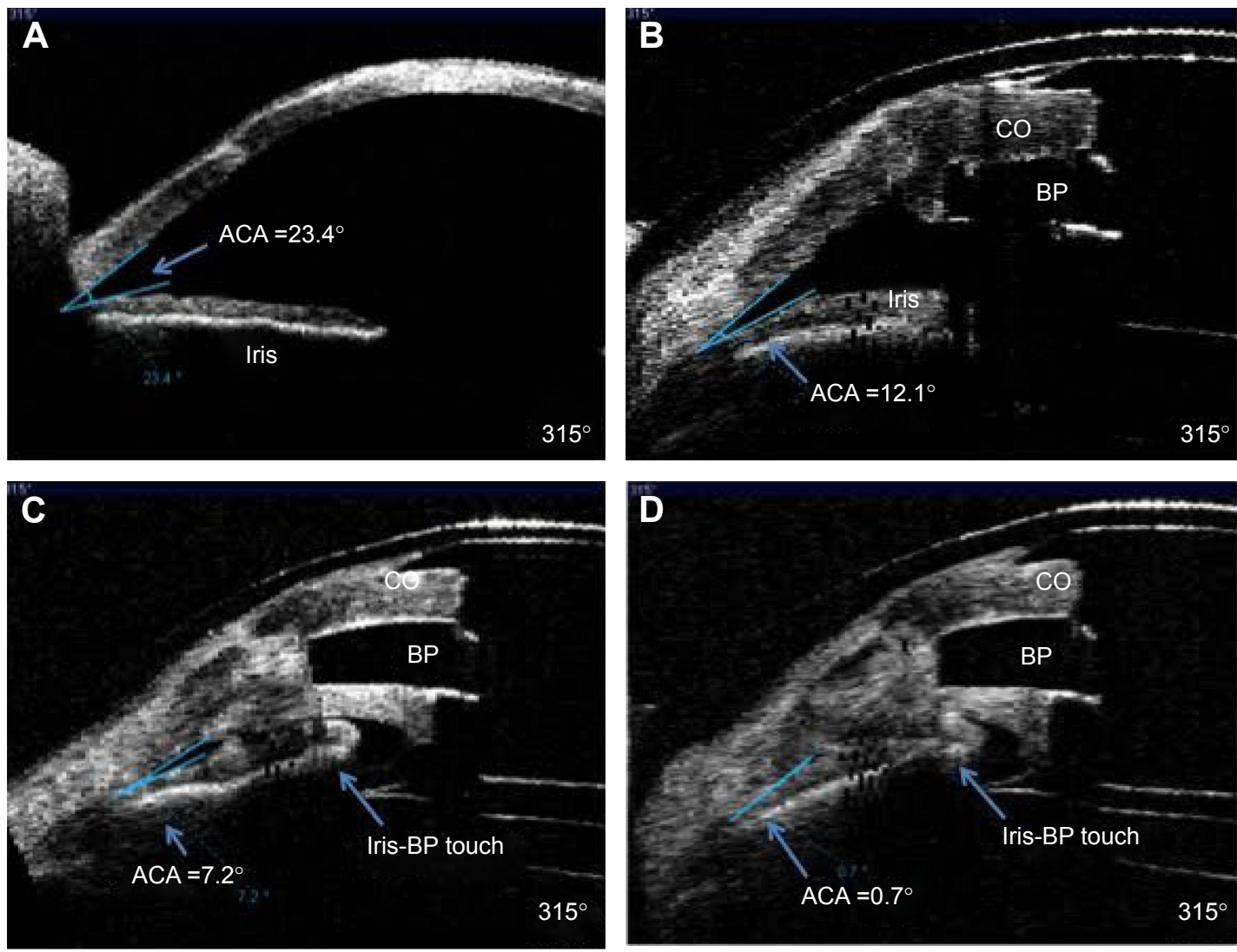

Figure 5 Progressive closure of the angle in a single patient following keratoprosthesis implantation.

Notes: Photo (A) demonstrates an open angle preoperatively. Photos B-D demonstrate progressive closure of the angle with ultimate iris-backplate touch. Reproduced with permission from Kang et al. Serial Analysis of Anterior Chamber Depth and Angle Status Using Anterior Segment Optical Coherence Tomography After Boston Keratoprosthesis. Cornea. 2013;32(10):1369-1374. ${ }^{31}$ Promotional and commercial use of the material in print, digital or mobile device format is prohibited without the permission from the publisher Wolters Kluwer Health. Please contact healthpermissions@wolterskluwer.com for further information.

Abbreviations: ACA, Anterior chamber angle; CO, Cornea; BP, Backplate.

\section{Disclosure}

The authors report no conflicts of interest in this work.

\section{References}

1. Khan B, Dudenhoefer EJ, Dohlman CH. Keratoprosthesis: an update. Curr Opin Ophthalmol. 2001;12(4):282-287.

2. Greiner MA, Li JY, Mannis MJ. Longer-term vision outcomes and complications with the Boston type 1 keratoprosthesis at the University of California, Davis. Ophthalmology. 2011;118(8):1543-1550.

3. Ciolino JB, Belin MW, Todani A, Al-Arfaj K, Rudnisky CJ; Boston Keratoprosthesis Type 1 Study Group. Retention of the Boston keratoprosthesis type 1: multicenter study results. Ophthalmology. 2013;120(6): $1195-1200$

4. Kang JJ, de la Cruz J, Cortina MS. Visual outcomes of Boston keratoprosthesis implantation as the primary penetrating corneal procedure. Cornea. 2012;31(12):1436-1440.

5. Nouri M, Terada H, Alfonso EC, Foster CS, Durand ML, Dohlman CH. Endophthalmitis after keratoprosthesis: incidence, bacterial causes, and risk factors. Arch Ophthalmol. 2001;119(4):484-489.

6. Sivaraman KR, Hou JH, Allemann N, de la Cruz J, Cortina MS. Retroprosthetic membrane and risk of sterile keratolysis in patients with type I Boston Keratoprosthesis. Am J Ophthalmol. 2013;155(5): 814-822.
7. Rudnisky CJ, Belin MW, Todani A, et al; Boston Type 1 Keratoprosthesis Study Group. Risk factors for the development of retroprosthetic membranes with Boston keratoprosthesis type 1: multicenter study results. Ophthalmology. 2012;119(5):951-955.

8. Colby KA, Koo EB. Expanding indications for the Boston keratoprosthesis. Curr Opin Ophthalmol. 2011;22:267-273.

9. Sayegh RR, Ang LP, Foster CS, Dohlman CH. The Boston keratoprosthesis in Stevens-Johnson syndrome. Am J Ophthalmol. 2008;145: 438-444.

10. Aldave AJ, Kamal KM, Vo RC, Yu F. The Boston type I keratoprosthesis: improving outcomes and expanding indications. Ophthalmology. 2009; 116(4):640-651.

11. Pineles SL, Ela-Dalman N, Rosenbaum AL, et al. Binocular visual function in patients with Boston type I keratoprostheses. Cornea. 2010;29: $1397-1400$.

12. Cortina MS, Hallak J. Vision-related quality-of-life assessment using NEI VFQ-25 in patients after Boston keratoprosthesis implantation. Cornea. 2015;34(2);160-164.

13. Kammerdiener LL, Speiser JL, Aquavella JV, et al. Protective effect of soft contact lenses after Boston keratoprosthesis. Br J Ophthalmol. $2015 ; 0: 1-4$

14. Ramaesh K, Ramaesh T, Dutton GN, Dhillon B. Evolving concepts on the pathogenic mechanisms of aniridia related keratopathy. Int $J$ Biochem Cell Biol. 2005;37:547-557. 
15. Massachusetts Eye and Ear Infirmary. Boston Keratoprosthesis update. Available from: http://www.masseyeandear.org/ /media/testupload/ files/2010-kpro-newsletter.pdf?la=en. Accessed December 21, 2015.

16. Sejpal K, Yu F, Aldave AJ. The Boston keratoprosthesis in the management of corneal limbal stem cell deficiency. Cornea. 2011;30(11): 1187-1194.

17. Nau AC, Drexler S, Dhaliwal DK, Mah F, Raju L, Deschler E. Contact lens fitting and long-term management for the Boston keratoprosthesis. Eye Contact Lens. 2014;40(3):185-189.

18. Vajaranant TS, Blair MP, McMahon T, Wilensky JT, de la Cruz J. Special considerations for pars plana tube-shunt placement in Boston type 1 keratoprosthesis. Arch Ophthalmol. 2010;128(11):1480-1482.

19. Law SK, Huang JS, Nassiri N, et al. Technique of combined glaucoma tube shunt and keratoprosthesis implantation. J Glaucoma. 2014; 23(8):501-507.

20. Huh ES, Aref AA, Vajaranant TS, de la Cruz J, Chau FY, Cortina MS. Outcomes of pars plana glaucoma drainage implant in Boston type 1 keratoprosthesis surgery. J Glaucoma. 2014;23(1):e39-e44.

21. Kiang L, Sippel KC, Starr CE, et al. Vitreoretinal surgery in the setting of permanent keratoprosthesis. Arch Ophthalmol. 2012;130(4): 487-492.

22. Todani A, Ciolino JB, Ament JD, et al. Titanium back plate for a PMMA keratoprosthesis: clinical outcomes. Graefes Arch Clin Exp Ophthalmol. 2011;249(10):1515-1518.

23. Paschalis E, Chodosh J, Spurr-Michaud S, et al. In vitro and in vivo assessment of titanium surface modification for coloring the backplate of the Boston keratoprosthesis. Invest Ophthalmol Vis Sci. 2013; 54(6):3863-3873.

24. Behlau I, Martin KV, Martin JN, et al. Infectious endophthalmitis in Boston keratoprosthesis: incidence and prevention. Acta Ophthalmol. 2014;92(7):e546-e555.

25. BOSTON KPro news. Antimicrobial prophylaxis for life: as important as ever. Fall 2011, Number 8. Available from: http://www.masseyeandear.org/ /media/testupload/files/2011-kpro-newsletter.pdf?la=en. Accessed December 21, 2015.

26. Durand ML, Dohlman CH. Successful prevention of bacterial endophthalmitis in eyes with the Boston keratoprosthesis. Cornea. 2009;28(8):896-901.
27. BOSTON KPro news. Boston KPro: Past Successes and Future Challenges. September 2015 | Number 11. Available from: http://www. masseyeandear.org/ /media/testupload/files/kpronewsletter 2015 web. pdf?la=en. Accessed December 21, 2015.

28. Ament JD, Pineda R, Lawson B, Belau I, Dohlman CH. The Boston Keratoprosthesis International Protocol Version 2. June 15, 2009.

29. Thomas M, Shorter E, Joslin CE, McMahon TJ, Cortina MS. Contact Lens Use in Patients With Boston Keratoprosthesis Type 1: Fitting, Management, and Complications. Eye Contact Lens. 2015;41(6):334-340.

30. Sayegh RR, Avena Diaz L, Vargas-Martín F, Webb RH, Dohlman CH, Peli E. Optical functional properties of the Boston Keratoprosthesis. Invest Ophthalmol Vis Sci. 2010;51(2):857-863.

31. Kang JJ, Allemann N, Cruz Jde L, Cortina MS. Serial Analysis of Anterior Chamber Depth and Angle Status Using Anterior Segment Optical Coherence Tomography After Boston Keratoprosthesis. Cornea. 2013;32(10):1369-1374.

32. Shapiro BL1, Cortés DE, Chin EK, et al. High-resolution spectral domain anterior segment optical coherence tomography in type 1 Boston keratoprosthesis. Cornea. 2013;32(7):951-955.

33. Qian CX, Hassanaly S, Harissi-Dagher M. Anterior segment optical coherence tomography in the long-term follow-up and detection of glaucoma in Boston type I keratoprosthesis. Ophthalmology. 2015; 122(2):317-325.

34. Fernandez AG, Radcliffe NM, Sippel KC, et al. Boston type I keratoprosthesis-donor cornea interface evaluated by high-definition spectral-domain anterior segment optical coherence tomography. Clin Ophthalmol. 2012;6:1355-1359.

35. Kamyar R, Weizer JS, de Paula FH, et al. Glaucoma associated with Boston type I keratoprosthesis. Cornea. 2012;31(2):134-139.

36. Panarelli JF, Ko A, Sidoti PA, Garcia JP, Banitt MR. Angle closure after Boston keratoprosthesis. J Glaucoma. 2013;22(9):725-729.

37. Garcia JP Jr, de la Cruz J, Rosen RB, Buxton DF. Imaging implanted keratoprostheses with anterior-segment optical coherence tomography and ultrasound biomicroscopy. Cornea. 2008;27(2):180-188.
Clinical Ophthalmology

\section{Publish your work in this journal}

Clinical Ophthalmology is an international, peer-reviewed journal covering all subspecialties within ophthalmology. Key topics include: Optometry; Visual science; Pharmacology and drug therapy in eye diseases; Basic Sciences; Primary and Secondary eye care; Patient Safety and Quality of Care Improvements. This journal is indexed on

\section{Dovepress}

PubMed Central and CAS, and is the official journal of The Society of Clinical Ophthalmology (SCO). The manuscript management system is completely online and includes a very quick and fair peer-review system, which is all easy to use. Visit http://www.dovepress.com/ testimonials.php to read real quotes from published authors. 